\title{
Risk factors for depth of infiltration in the differentiated depressed early gastric carcinoma: a preliminary analysis
}

Shu-dong Yang ${ }^{1 \dagger}$, Zhi-xin Qian ${ }^{2 \dagger}$, Qiang Zhan ${ }^{3^{*}}$, Qun-yan Zhou ${ }^{3}$ and Guo-min Lu ${ }^{3}$

\begin{abstract}
Background: To analyze the clinicopathologic factors associated with mucosal and submucosal infiltration in differentiated depressed early gastric cancer, and screening factors that can predict depth of infiltration before endoscopic treatment.
\end{abstract}

Methods: The study included 35 cases of mucosal carcinomas and 66 cases of submucosal carcinomas according to the pathological diagnosis. The relevant clinicopathologic factors were investigated by univariate and multivariate analysis.

Results: The average depth of the depressed lesions for the submucosal group was significantly more than that for the mucosal group. The proportion of the lesions with rough bottom surface and abnormal surrounding folds was significantly higher in the submucosal group compared to that in the mucosal group. Logistic regression analysis indicated that the above-mentioned three factors were independent risk factors that could be used to predict mucosal and submucosal infiltration. Area under the curve (AUC) of receiver operating characteristic (ROC) of the ordinal above-mentioned three factors for predicting submucosal infiltration was $0.716,0.663,0.704$, respectively. Stratified analysis showed that the $100 \%$ cases with lesion depth $\geq 2.5 \mathrm{~mm}$ and rough bottom surface developed submucosal infiltration regardless of the morphological changes of the folds.

Conclusion: The study identified independent risk factors for predicting mucosal and submucosal infiltration in depressed differentiated early gastric cancer, which may evaluate the degree of penetration before endoscopic treatment.

Virtual Slides: The virtual slide(s) for this article can be found here: http://www.diagnosticpathology.diagnomx.eu/ vs/13000_2014_206

Keywords: Differentiated depressed early gastric cancer, Depth of infiltration, Clinicopathologic factor

\section{Background}

Endoscopic mucosal resection (EMR) and endoscopic submucosal dissection (ESD) have become one of the standard treatment methods for early-stage gastric cancer in Japan. The development of these two endoscopic technologies has benefited from research on two screening criteria for operability for endoscopic resection. Yamao et al. [1] and Gotoda et al [2], investigated thousands of patients with

\footnotetext{
* Correspondence: zhanq33@163.com

'Equal contributors

${ }^{3}$ Department of Gastroenterology, Wuxi People's Hospital Affiliated with Nanjing Medical University, Wuxi 214023, China

Full list of author information is available at the end of the article
}

early gastric cancer who received gastrectomy and lymph node dissection, and assessed the clinicopathological factors for their possible association with lymph node metastasis. They eventually developed evaluation criteria for EMR and ESD treatment of early gastric cancer before surgery.

EMR and ESD are therapeutic endoscopic techniques that offer the advantage of acquiring specimens from the lesion for pathological analysis. These have become the most accurate approaches for the diagnosis of early gastric cancer. For instance, results of the pathological examination can confirm the cure or suggest additional treatment. The disease-specific 5- and 10-year survival rates 
can reach $99 \%$ for patients who meet the above evaluation criteria for EMR treatment of early gastric cancer before surgery [3].

Early gastric ESD offers the advantage of high percentage of enbloc resection rates. According to a published report, enbloc resection rates of $92.7 \%$ and curative resection rates of $73.6 \%$ were achieved [4]. Local recurrence of early gastric cancer after ESD treatment was less than $2 \%$ [5]. It is worth noting that the healing effects similar to those obtained with traditional surgical treatment could be achieved only if the lesions met the criteria for curative resection, highlighting the importance of accurate pre and post-operative assessment. The mistakes in preoperative evaluation do occur (error rate was $7 \%$ in the EMR group and $16 \%$ in the ESD group) and are confirmed by postoperative pathological examination.4 According to preoperative indications defined by Japanese Gastric Cancer Association (JGCA) [6,7], endoscopic examination and endoscopic biopsy are sufficient to evaluate the diameter of the lesion, formation of ulcer and the pathological type of early gastric cancer. However, practical and putative criteria to evaluate the depth of mucosal or submucosal infiltration are still lacking.

Given the difficulty in determining the depth of infiltration in the depressed early gastric cancer, we followed the method of Yamao $\mathrm{T}$ and Gotoda $\mathrm{T}$ [1,2], and retrospectively reviewed the clinicopathological characteristics of mucosal and submucosal gastric cancer in order to identify the factors for preoperative evaluation in gastric cancer.

\section{Methods}

\section{Subjects and inclusion/exclusion criteria}

Patients who had been diagnosed for depressed early gastric cancer at Wuxi People's Hospital Affiliated with Nanjing Medical University between January 2005 and December 2011 were recruited for this study. The subjects received surgical resection and lymphadenectomy and the pathological analysis confirmed diagnosis of differentiated type early gastric cancer. Cases with undifferentiated type early gastric cancer were excluded due to the controversy surrounding the use of endoscopy for such types of gastric cancer. All case diagnoses were made by a pathologist with 16 years clinical experience and confirmed by an independent pathologist with over 40 years clinical experience. Informed consents were obtained from all subjects, and the study was approved by the medical ethics committee of People's Hospital of Wuxi, an affiliated hospital of Nanjing Medical University.

\section{Test parameters}

According to the classification of gastric cancer based on the guidelines laid out by JGCA [7], the lesions were grouped as: type I (elevated), type II and type III (depressed). Type II can be sub-classified into: type IIa (surface elevated), type IIb (flat) and type IIc (surface depressed). Both type III and type IIc were considered as depressed lesions.

The following clinical data were acquired: (1) gender; (2) age; (3) location of the lesions (stomach was divided into upper $1 / 3$, middle $1 / 3$ and lower $1 / 3$ based on JGCA guidelines;7 (4) size of the lesion (largest diameter of the bottom surface of depressed area); (5) presence of ulcer (obvious ulcer or scarring evidence of a previous ulcer); (6) depth of the lesion (measured as the distance between planes of the specimen mounted on a pathology slide from the highest point of the lesion edge to the lowest point of the lesion basilar portion); (7) bottom of the lesion: smooth or rough (surface is not flat with particle-like bulge or small mucosal island); (8) folds surrounding the lesions: normal folds were marked as negative and broken folds or enlarged/fusion folds were marked as positive; (9) degree of gastric cancer differentiation: highly differentiated was defined as grade I cancer and moderately differentiated was defined as grade II cancer; (10) depth of infiltration: the lesions were classified as mucosal gastric cancer or submucosal gastric cancer.

\section{Statistical analysis}

The data were processed using SPSS 17.0 software (SPSS Inc., Chicago, IL). All the samples were classified into the mucosal group and the submucosal group based on the depth of infiltration. T test or Wilcoxon rank test were used to process quantitative data, and categorical data were processed by chi-square test. Logistic regression multiple factor analysis was used to evaluate independent factors that influenced the mucosal/submucosal infiltration of early gastric cancer. Receiver Operating Characteristic (ROC) curves of independent factors were plotted based on the above results of Logistic regression analysis to reflect morphological factors, which may affect the depth of infiltration. The area under the curve (AUC) was calculated and cut-off values were estimated. Stratified analysis was performed for statistically significant morphological factors to evaluate the distribution of mucosal and submucosal groups in various conditions. $\mathrm{P}<0.05$ was defined as statistically significant.

\section{Results}

A total of 101 cases with depressed lesions were evaluated (35 cases in the mucosal group, 34.7\%, Figure 1; 66 cases in the submucosal group, 65.3\%, Figure 2). General patient information and clinicopathologic data are shown in Tables 1 and 2 .

\section{Univariate analysis of the depressed lesions}

Univariate analysis was applied to the data of acquired characteristics. T test or Wilcoxon rank test were used 


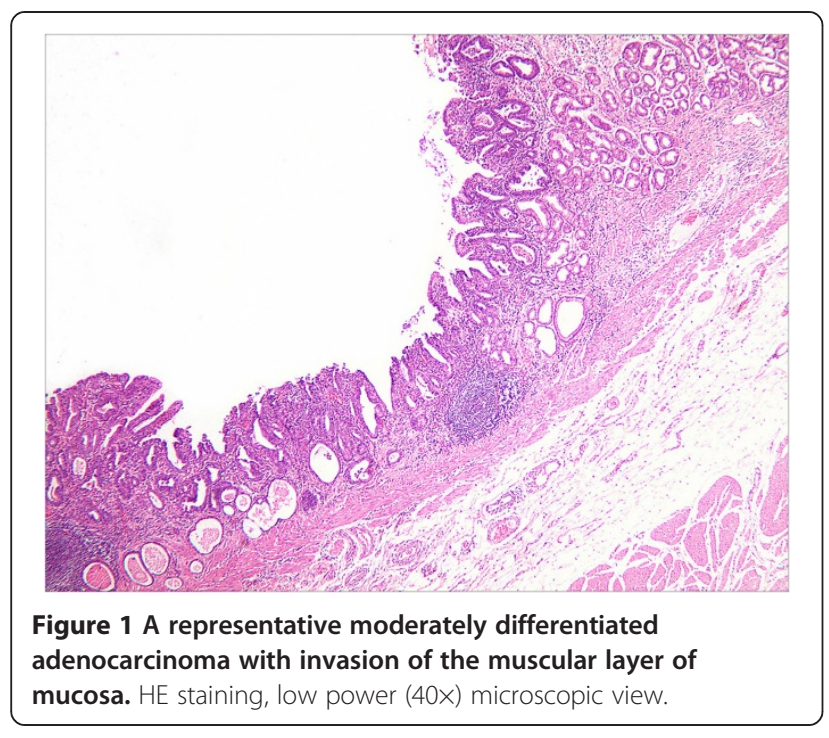

to process quantitative data, and categorical data were processed by chi-square test. Results showed that the lesion depth of the submucosal group (average $3.9 \pm$ $2.5 \mathrm{~mm}$ ) was more than that of the mucosal group (average $2.3 \pm 1.5 \mathrm{~mm}$ ). The analysis of the bottom of the lesion showed that the mucosal group had 30 (85.7\%) cases with smooth bottom and 5 (14.3\%) cases with rough bottom, while the submucosal group had 35 (53.0\%) cases of smooth bottom and 31 (47.0\%) cases of rough bottom. The analysis of folds surrounding the lesions showed that the mucosal group had 27 (77.1\%) cases with normal folds and $8(22.9 \%)$ cases with abnormal folds, while the submucosal group had 24 (36.4\%) cases with normal folds and 42 (63.6\%) cases with abnormal folds. The submucosal group showed higher rates of rough bottom surface and abnormal folds compared

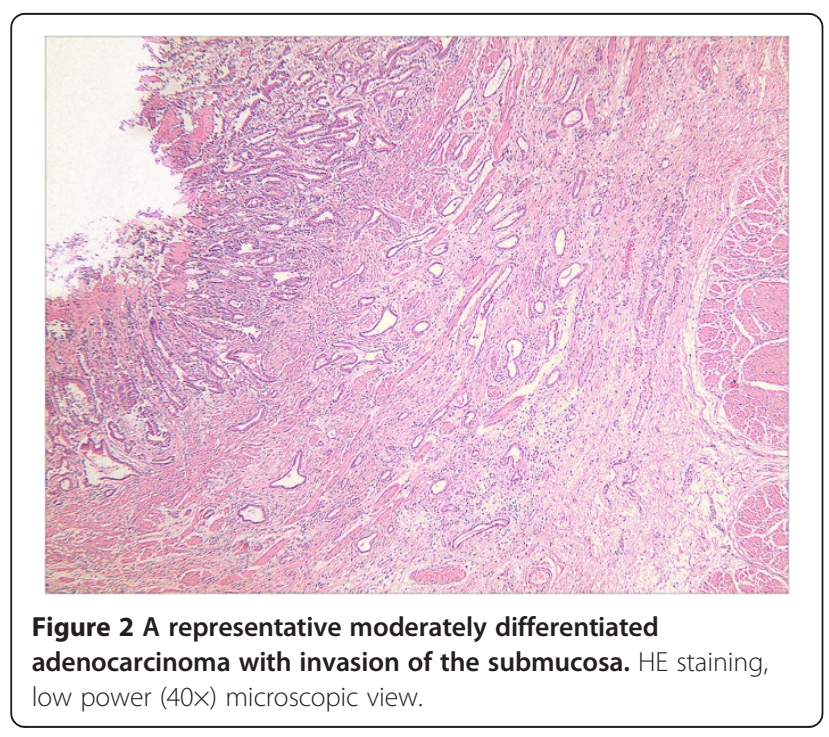

Table 1 General patient information

\begin{tabular}{|c|c|c|c|c|}
\hline \multirow{3}{*}{ Patient data } & \multicolumn{4}{|c|}{$\mathrm{N}=101$} \\
\hline & \multicolumn{2}{|c|}{$\begin{array}{l}\text { Males, } \\
\mathrm{N}=71\end{array}$} & \multicolumn{2}{|c|}{$\begin{array}{l}\text { Females, } \\
\mathrm{N}=\mathbf{3 0}\end{array}$} \\
\hline & Yes & No & Yes & No \\
\hline Upper abdominal pain & 50 & 21 & 19 & 11 \\
\hline Abdominal distention & 41 & 30 & 19 & 11 \\
\hline Decreased food appetite & 16 & 55 & 5 & 25 \\
\hline Nausea & 25 & 46 & 11 & 19 \\
\hline Vomiting & 3 & 68 & 3 & 27 \\
\hline Acid regurgitation & 5 & 66 & 3 & 27 \\
\hline Belching & 16 & 55 & 14 & 16 \\
\hline Haematemesis & 5 & 66 & 0 & 30 \\
\hline Black stool & 14 & 57 & 0 & 30 \\
\hline Weight loss & 9 & 62 & 3 & 27 \\
\hline Fatigue & 7 & 64 & 3 & 27 \\
\hline History of hypertension & 27 & 44 & 16 & 14 \\
\hline History of coronary heart disease & 5 & 66 & 0 & 30 \\
\hline History of diabetes mellitus & 11 & 60 & 8 & 22 \\
\hline History of hepatitis & 5 & 66 & 0 & 30 \\
\hline History of cirrhosis & 3 & 68 & 0 & 30 \\
\hline Long-term* history of smoking & 13 & 58 & 0 & 30 \\
\hline Long-term** history of drinking alcohol & 3 & 68 & 0 & 30 \\
\hline Long-term ${ }^{* *}$ oral administration of aspirin & 3 & 68 & 0 & 30 \\
\hline Special occupation & $3^{* * * *}$ & 68 & 0 & 30 \\
\hline Family history & 5 & 66 & 3 & 27 \\
\hline
\end{tabular}

${ }^{*} 15-30$ years; ${ }^{* *} 7-15$ years; ${ }^{* * * 3-5}$ years; ${ }^{* * *}$ All cases were dust-exposure.

to the mucosal group. The collective data is presented in Table 3.

\section{Multivariate analysis of depressed lesions}

According to the results of univariate analysis, logistic binary regression model was used to evaluate the size, depth, bottom surface, and surrounding folds of the lesions $(\mathrm{P}<0.1)$. Regression model was established using forward stepwise regression, and the results obtained from the three-step regression analysis showed that depth, surface roughness and surrounding folds of the lesions are independent predictors of tumor filtration (Table 4).

\section{Diagnostic performance of independent morphological factors of the depressed lesions for predicting submucosal infiltration}

We further plotted ROC curves to estimate the diagnostic performance of the three independent predictors: depth, surface roughness and surrounding folds of the depressed lesions in gastric cancer (Figure 3). AUCs of depth, surface roughness and surrounding folds of the 
Table 2 Clinical and pathological characteristics of the patients

\begin{tabular}{llll}
\hline Characteristic & & N & Percentage (\%) \\
\hline Sex & Male & 71 & 70.3 \\
& Female & 30 & 29.7 \\
Age in years & & $61.2 \pm 9.8$ & \\
Location of lesions & Upper 1/3 & 24 & 23.8 \\
& Middel 1/3 & 30 & 29.7 \\
& Lower 1/3 & 47 & 46.5 \\
Size of the lesions & $15.5 \pm 12.3$ & & \\
in mm & & & \\
Presence of ulcer & No & 53 & 52.5 \\
& Yes & 48 & 47.5 \\
$\begin{array}{l}\text { Depth of depressed } \\
\text { lesions in mm }\end{array}$ & $3.4 \pm 2.4$ & & \\
Roughness of the & Smooth & 65 & 64.4 \\
bottom & Rough & 36 & 35.6 \\
Surrounding folds & Normal & 51 & 50.5 \\
& Abnormal & 50 & 49.5 \\
Degree of & Highly & 10 & 9.9 \\
differentiation & differentiated & & \\
& Moderately & 91 & 91.1 \\
& differentiated & & \\
\hline Data a pres & &
\end{tabular}

Data are presented as $\mathrm{N}$ or mean $\pm \mathrm{SD}$. lesions were 0.716 ( $\mathrm{P}=0.000,95 \% \mathrm{CI}$ 0.613-0.819), 0.663 $(\mathrm{P}=0.007,95 \% \mathrm{CI}$ 0.556-0.771) and 0.704 $(\mathrm{P}=0.001$, 95\% CI 0.598-0.810), respectively. The optimal cut-off value of depth of depressed lesions for predicting submucosal infiltration was $2.5 \mathrm{~mm}$ based on Youden's index (Table 5).

\section{Stratified analysis}

Based on the cut-off value of $2.5 \mathrm{~mm}$, the lesions were divided into two groups: $<2.5 \mathrm{~mm}$ group and $\geq 2.5 \mathrm{~mm}$ group. Stratified analysis suggested that $100 \%$ of the lesions in early, depressed gastric cancer with depth $\geq 2.5 \mathrm{~mm}$, rough bottom surface and normal/abnormal surrounding folds developed submucosal infiltration (Table 6).

\section{Discussion}

Endoscopic mucosal resection (EMR) and endoscopic submucosal dissection (ESD) are widely accepted endoscopic techniques for treating early gastric cancer. The indications for applying endoscopic therapy are: differentiated type early gastric cancer; no evidence of lymph node metastasis; infiltration is confined to mucosal or minute submucosal infiltration [8]. The rate of lymph node metastasis is less than $3 \%$ when the gastric cancer is confined to mucosal infiltration [9]. However, submucosal infiltration leads to a higher risk of metastasis [10]. Due to frequent submucosal infiltration and lymph node metastasis [11], evaluation of the depth of infiltration of depressed type of early gastric cancer is crucial for decisions regarding the therapeutic regimen $[8,12]$.

Table 3 Univariate analysis of differentiated depressed early gastric carcinoma

\begin{tabular}{|c|c|c|c|c|c|}
\hline \multirow[t]{2}{*}{ Factors } & & \multicolumn{2}{|l|}{ Values } & \multirow[t]{2}{*}{ Statistical value } & \multirow[t]{2}{*}{$p$ value } \\
\hline & & Mucosal gastric cancer & Submucosal gastric cancer & & \\
\hline \multirow[t]{2}{*}{$\overline{\operatorname{Sex}}$} & Male & $24(66.2)$ & $47(71.2)$ & $x^{2}=0.076$ & 0.782 \\
\hline & Female & $11(33.8)$ & $19(28.8)$ & & \\
\hline Age in years & & $62.3 \pm 9.2$ & $60.6 \pm 10.2$ & $t=0.402$ & 0.843 \\
\hline \multirow[t]{3}{*}{ Lesion location } & Upper $1 / 3$ & $6(17.1)$ & $18(27.3)$ & $x^{2}=1.994$ & 0.369 \\
\hline & Middle 1/3 & $13(37.2)$ & $17(25.7)$ & & \\
\hline & Lower $1 / 3$ & $16(45.7)$ & $31(47.0)$ & & \\
\hline Size of the lesion in $\mathrm{mm}$ & & $12.4 \pm 10.8$ & $17.2 \pm 12.8$ & $U=894.0$ & 0.061 \\
\hline \multirow[t]{2}{*}{ Ulcer } & Absence & $22(62.9)$ & $31(47.0)$ & $x^{2}=2.315$ & 0.128 \\
\hline & Presence & $13(37.1)$ & $35(53.0)$ & & \\
\hline Depth in mm & & $2.3 \pm 1.5$ & $3.9 \pm 2.5$ & $U=656.5$ & 0.000 \\
\hline \multirow[t]{2}{*}{ Roughness of the bottom } & Smooth & $30(85.7)$ & $35(53.0)$ & $x^{2}=10.651$ & 0.001 \\
\hline & Rough & $5(14.3)$ & $31(47.0)$ & & \\
\hline \multirow[t]{2}{*}{ Surrounding folds } & Normal & $27(77.1)$ & $24(36.4)$ & $x^{2}=15.215$ & 0.000 \\
\hline & Abnormal & $8(22.9)$ & $42(63.6)$ & & \\
\hline \multirow[t]{2}{*}{ Degree of differentiation } & Highly differentiated & $4(11.4)$ & $6(9.1)$ & $x^{2}=0.140$ & 0.708 \\
\hline & Moderately differentiated & 31 (88.6) & $60(90.9)$ & & \\
\hline
\end{tabular}


Table 4 Multivariate analysis of differentiated depressed early gastric carcinoma

\begin{tabular}{|c|c|c|c|c|c|c|c|c|}
\hline \multirow{3}{*}{ 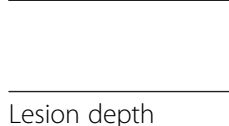 } & \multirow[t]{2}{*}{ B } & \multirow[t]{2}{*}{ S.E. } & \multirow[t]{2}{*}{ Wals } & \multirow[t]{2}{*}{ df } & \multirow[t]{2}{*}{ Sig. } & \multirow{2}{*}{$\begin{array}{l}\text { Exp } \\
\text { (B) }\end{array}$} & \multicolumn{2}{|c|}{$\operatorname{Exp}(\mathrm{B}) 95 \% \mathrm{Cl}$} \\
\hline & & & & & & & Lower limit & Upper limit \\
\hline & 0.425 & 0.151 & 7.949 & 1 & 0.005 & 1.530 & 1.138 & 2.056 \\
\hline Bottom roughness & 1.348 & 0.608 & 4.918 & 1 & 0.027 & 3.851 & 1.170 & 12.681 \\
\hline Surrounding folds & 1.448 & 0.520 & 7.746 & 1 & 0.005 & 4.254 & 1.535 & 11.794 \\
\hline
\end{tabular}

Abbreviations: $B$ regression coefficient, S.E. standard error, Wals the square of the ratio of the regression coefficient and standard error, $d f$ degrees of freedom, Sig probability, $\operatorname{Exp}(B)$ the exponential function, and is the result of regression coefficient $\mathrm{B}$ value index calculation, $\mathrm{Cl}$ confidence interval.

There is no consensus on the preoperative diagnosis of the depth of infiltration. Computed tomography (CT) scan does not assess the depth of tumor invasion [13]. The use of endoscopic ultrasonography is also controversial in determining the depth of infiltration [14]. A summary of 18 studies suggested that sensitivity varied from $18.2 \%$ to $100 \%$ (average $87.8 \%$ ) and specificity varied from $34.7 \%$ to $100 \%$ (average $80.2 \%$ ) when using endoscopic ultrasound for the diagnosis of submucosal invasion of early gastric cancer [15]. It was concluded that it is not a mature method for differentiating between mucosal and submucosal infiltration. Traditionally, gastroscopy has been used for early gastric cancer staging with an accuracy of $79.0 \%$, which is similar to that achieved by endoscopic ultrasound [16-18]. Thus, ordinary endoscopy could provide sufficient information to determine the best treatment options for the resection of early gastric cancer.

Our study identified independent predictive factors for infiltration based on the analysis of multiple clinical and pathomorphological data. We further applied stratified

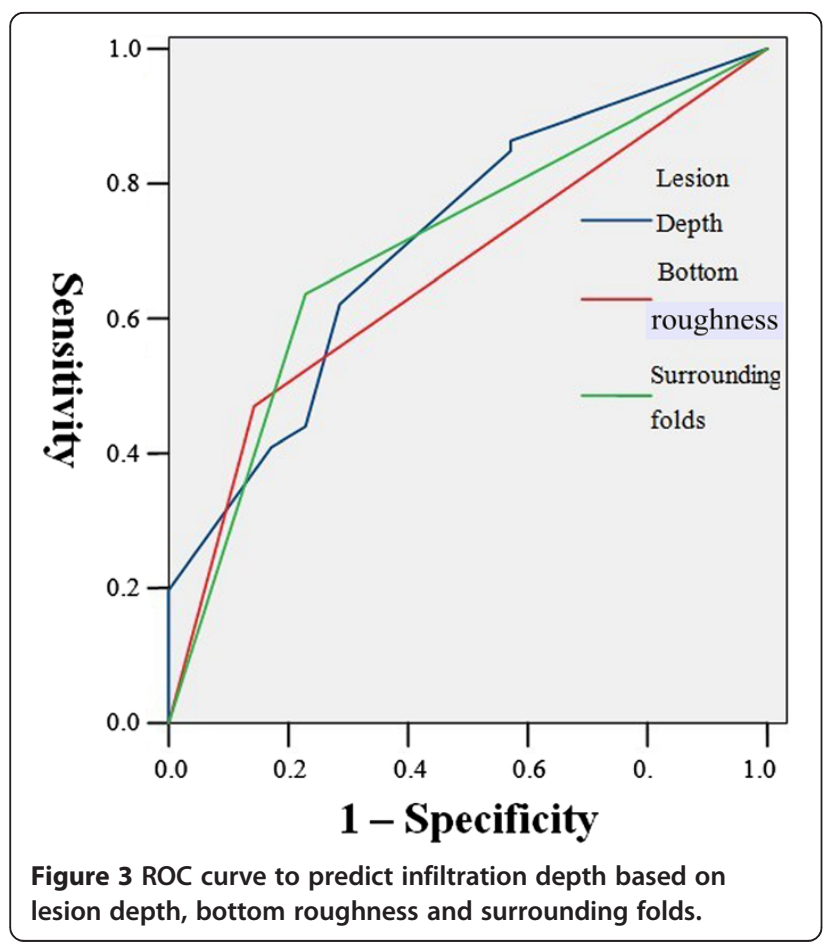

analysis to these factors to predict the depth of filtration. It was reported that the diameter of the lesion is associated with the depth of infiltration of gastric cancer [19], but our results indicated that there was no significant difference between mucosal and submucosal groups. Besides, only seven cases of depressed lesions among 37 cases of gastric cancer were included [19], which limits the analysis performed in that study. The parameters, such as the location of the lesion, presence of ulcer and histology type are irrelevant to the depth of filtration, which is consistent with a previously published study [20]. ROC curve analysis further illustrates the value of the three factors for the diagnosis of lesion infiltration. Among the three factors, the depth of the lesion is superior to the lesion bottom roughness and surrounding folds in term of its value for making a diagnosis. Our findings that the presence of rough bottom surface and irregular folds also aid in the diagnosis of submucosal gastric cancer are in agreement with a pervious study [21].

It should be noted that in this study, the converging folds were considered as ulcer but not the abnormal changes of the surrounding folds. Only the broken and enlarged folds were defined as abnormal folds. The formation of ulcers and subsequent scarring and converging fold normally indicate tissue fibrosis but do not necessarily suggest penetration of tumor, although some gastric cancers with converging folds are confined to the

Table 5 ROC curve and Youden's index based on the depth of the lesions

\begin{tabular}{lllll}
\hline Lesion depth & Sensitivity & Specificity & 1-specificity & Youden's index \\
\hline 0.000 & 1.000 & 0.000 & 1.000 & 0.000 \\
1.250 & 0.864 & 0.429 & 0.571 & 0.293 \\
1.750 & 0.848 & 0.429 & 0.571 & 0.277 \\
$2.500^{\mathrm{b}}$ & 0.621 & 0.714 & 0.286 & 0.315 \\
3.500 & 0.439 & 0.771 & 0.229 & 0.210 \\
4.500 & 0.409 & 0.829 & 0.171 & 0.238 \\
5.500 & 0.197 & 1.000 & 0.000 & 0.197 \\
6.000 & 0.167 & 1.000 & 0.000 & 0.167 \\
7.500 & 0.121 & 1.000 & 0.000 & 0.121 \\
9.000 & 0.061 & 1.000 & 0.000 & 0.061 \\
11.000 & 0.000 & 1.000 & 0.000 & 0.000 \\
\hline
\end{tabular}

${ }^{\mathrm{a}}$ Youden's index $=$ (sensitivity + specificity) $-1 ;{ }^{b}$ the optimal cut-off value. 
Table 6 Stratified analysis of the differentiated depressed early gastric carcinoma

\begin{tabular}{|c|c|c|c|c|c|c|c|}
\hline \multirow{2}{*}{$\begin{array}{l}\text { Lesion } \\
\text { depth }\end{array}$} & \multicolumn{4}{|c|}{ Bottom roughness } & \multicolumn{2}{|c|}{ Grouping based on penetration depth } & \multirow[t]{2}{*}{ Sum } \\
\hline & & & & & Mucosal surface & Submucosal surface & \\
\hline \multirow[t]{8}{*}{$<2.5 \mathrm{~mm}$} & Smooth & Surrounding folds & No & Count & 16 & 7 & 23 \\
\hline & & & & Percentage & $69.5 \%$ & $31.5 \%$ & $100.0 \%$ \\
\hline & & & Yes & Count & 4 & 6 & 10 \\
\hline & & & & Percentage & $40.0 \%$ & $60.0 \%$ & $100.0 \%$ \\
\hline & Rough & Surrounding folds & No & Count & 4 & 4 & 8 \\
\hline & & & & Percentage & $50.0 \%$ & $50.0 \%$ & $100.0 \%$ \\
\hline & & & Yes & Count & 1 & 8 & 9 \\
\hline & & & & Percentage & $11.1 \%$ & $88.9 \%$ & $100.0 \%$ \\
\hline \multirow[t]{8}{*}{$\geq 2.5 \mathrm{~mm}$} & Smooth & Surrounding folds & No & Count & 7 & 11 & 16 \\
\hline & & & & Percentage & $43.8 \%$ & $56.2 \%$ & $100.0 \%$ \\
\hline & & & Yes & Count & 3 & 11 & 14 \\
\hline & & & & Percentage & $21.4 \%$ & $79.6 \%$ & $100.0 \%$ \\
\hline & Rough & Surrounding folds & No & Count & 0 & 2 & 2 \\
\hline & & & & Percentage & $0.0 \%$ & $100.0 \%$ & $100.0 \%$ \\
\hline & & & Yes & Count & 0 & 17 & 17 \\
\hline & & & & Percentage & $0.0 \%$ & $100.0 \%$ & $100.0 \%$ \\
\hline
\end{tabular}

mucosal layer [22]. However, the folds may break or enlarge when the top of the folds are infiltrated by the tumor. If annular dike appears, the tumor may have invaded the muscular layer. Thus, abnormal folds but not the presence or absence of ulcers may provide useful information for evaluating the depth of penetration in differentiated gastric cancer.

Based on the Youden's index derived from the ROC curve, we defined $2.5 \mathrm{~mm}$ as the cut-off value to divide the lesions into two groups (lesion depth $<2.5 \mathrm{~mm}$ or $\geq 2.5 \mathrm{~mm}$ ). Indeed, cases with lesion depth $\geq 2.5 \mathrm{~mm}$ with rough bottom surface had $100 \%$ submucosal penetration, regardless of the status of the surrounding folds. However, $69.5 \%$ cases with lesion depth $<2.5 \mathrm{~mm}$, smooth bottom and normal surrounding folds were confined to the mucosa. However, we measured the depth using specimens mounted on glass slides for pathological analysis; as such, the distance is expected to have been affected (shrunk by $10-20 \%$ ) by the formalin fixation and dehydration processes that are required for slide preparation. Our study aimed to reflect the conditions found under endoscopy and before any biopsy is taken. Therefore, the cut-off value of $2.5 \mathrm{~mm}$ may actually be $3 \mathrm{~mm}$ in living stomach. It is important that any future research studies, either from our lab or others, should design and use measurement methods that will reduce this kind of error.

\section{Conclusions}

Overall, we identified lesion depth, bottom roughness and surrounding folds as independent predictive factors for evaluating mucosal or submucosal infiltration in depressed gastric cancer based on retrospective analysis of the pathology samples. The results indicate that further studies from multiple centers and with larger sample sizes are required.

\section{Competing interests}

The author(s) declared no potential competing interest in the manuscript, including financial, consultant, institutional and other relationships.

\section{Authors' contributions}

SY and ZQ participated in the design of the study, performed the statistical analysis and draft the manuscript. QZ conceived of the study, and participated in its design and coordination and helped to draft the manuscript. QZ and GL collected, analyzed and organized cases data. All authors read and approved the final manuscript.

\section{Acknowledgements}

We thank Medjaden Bioscience Limited for assisting in the preparation of this manuscript. We thank Dr. Rong-chao Sun for conducting the independent diagnostic review of all cases.

\section{Author details}

'Department of Pathology, Wuxi People's Hospital Affiliated with Nanjing Medical University, Wuxi 214023, China. ${ }^{2}$ Department of Internal Medicine, Jiangsu Taizhou People's Hospital, Taizhou 225300, China. ${ }^{3}$ Department of Gastroenterology, Wuxi People's Hospital Affiliated with Nanjing Medical University, Wuxi 214023, China.

Received: 26 May 2014 Accepted: 8 October 2014

Published online: 30 October 2014

\section{References}

1. Yamao T, Shirao K, Ono H, Kondo H, Saito D, Yamaguchi H, Sasako M, Sano T, Ochiai A, Yoshida S: Risk factors for lymph node metastasis from intramucosal gastric carcinoma. Cancer 1996, 77:602-606.

2. Gotoda T, Yanagisawa A, Sasako M, Ono H, Nakanishi Y, Shimoda T, Kato Y: Incidence of lymph node metastasis from early gastric cancer: 
estimation with a large number of cases at two large centers. Gastric Cancer 2000, 3:219-225.

3. Uedo N, lishi H, Tatsuta M, Ishihara R, Higashino K, Takeuchi Y, Imanaka K, Yamada T, Yamamoto S, Yamamoto S, Tsukuma H, Ishiguro S: Longterm outcomes after endoscopic mucosal resection for early gastric cancer. Gastric Cancer 2006, 9:88-92.

4. Oda I, Saito D, Tada M, lishi H, Tanabe S, Oyama T, Doi T, Otani Y, Fujisaki J, Ajioka Y, Hamada T, Inoue H, Gotoda T, Yoshida S: A multicenter retrospective study of endoscopic resection for early gastric cancer. Gastric Cancer 2006, 9:262-270.

5. Chaves DM, Maluf Filho F, De Moura EG, Santos ME, Arrais LR, Kawaguti F, Sakai P: Endoscopic submucosal dissection for the treatment of early esophageal and gastric cancer-initial experience of a western center. Clinics (Sao Paulo) 2010, 65:377-382.

6. Ono S, Fujishiro M, Niimi K, Goto O, Kodashima S, Yamamichi N, Omata M: Technical feasibility of endoscopic submucosal dissection for early gastric cancer in patients taking anti-coagulants or anti-platelet agents. Dig Liver Dis 2009, 41:725-728.

7. Japanese Gastric Cancer Association: Japanese classification of gastric carcinoma. 2nd English Edition. Gastric Cancer 1998, 1:11.

8. Kim SG: Estimation by gross findings in early gastric cancer. Clin Endosc 2012, 45:245-247.

9. Sano T, Kobori O, Muto T: Lymph node metastasis from early gastric cancer: endoscopic resection of tumour. Br J Surg 1992, 79:241-244.

10. Li Y, Zhao Q, Fan LQ, Tan BB, Zhang ZD, Liu Y: Analysis of Lymph Node Dissection Range-Related Factors for Early Gastric Cancer Operation. Hepatogastroenterology 2013, 60:971-974.

11. Nakamura T, Yao T, Kakeji Y, Anai H, Morita M, Oda Y, Maehara Y: Depressed type of intramucosal differentiated-type gastric cancer has high cell proliferation and reduced apoptosis compared with the elevated type. Gastric Cancer 2013, 16:94-99.

12. Noh H, Park JJ, Yun JW, Kwon M, Yoon DW, Chang WJ, Oh HY, Joo MK, Lee BJ, Kim JH, Yeon JE, Kim JS, Byun KS, Bak YT: Clinicopathologic characteristics of patients who underwent curative additional gastrectomy after endoscopic submucosal dissection for early gastric cancer or adenoma. Korean $J$ Gastroenterol 2012, 59:289-295.

13. Lim JS, Yun MJ, Kim MJ, Hyung WJ, Park MS, Choi JY, Kim TS, Lee JD, Noh SH, Kim KW: CT and PET in stomach cancer: preoperative staging and monitoring of response to therapy. Radiographics 2006, 26:143-156

14. Okada K, Fujisaki J, Kasuga A, Omae M, Yoshimoto K, Hirasawa T, Ishiyama A, Yamamoto Y, Tsuchida T, Hoshino E, Igarashi M, Takahashi H: Endoscopic ultrasonography is valuable for identifying early gastric cancers meeting expanded-indication criteria for endoscopic submucosal dissection. Surg Endosc 2011, 25:841-848.

15. Kwee RM, Kwee TC: The accuracy of endoscopic ultrasonography in differentiating mucosal from deeper gastric cancer. Am J Gastroenterol 2008, 103:1801-1809.

16. Ahn HS, Lee HJ, Yoo MW, Kim SG, Im JP, Kim SH, Kim WH, Lee KU, Yang HK: Diagnostic accuracy of $\mathrm{T}$ and $\mathrm{N}$ stages with endoscopy, stomach protocol $\mathrm{CT}$, and endoscopic ultrasonography in early gastric cancer. J Surg Oncol 2009, 99:20-27.

17. Choi J, Kim SG, Im JP, Kim JS, Jung HC, Song IS: Comparison of endoscopic ultrasonography and conventional endoscopy for prediction of depth of tumor invasion in early gastric cancer. Endoscopy 2010, 42:705-713.

18. Choi J, Kim SG, Im JP, Kim JS, Jung HC, Song IS: Is endoscopic ultrasonography indispensable in patients with early gastric cancer prior to endoscopic resection? Surg Endosc 2010, 24:3177-3185.

19. Guo M, Liu H: Pathological char acter of early gastric cancer. Chin J Curr Clin Med 2008, 6:300-301.

20. Abe S, Oda I, Shimazu T, Kinjo T, Tada K, Sakamoto T, Kusano C, Gotoda T: Depth-predicting score for differentiated early gastric cancer. Gastric Cancer 2011, 14:35-40
21. Choi J, Kim SG, Im JP, Kim JS, Jung HC, Song IS: Endoscopic prediction of tumor invasion depth in early gastric cancer. Gastrointest Endosc 2011, 73:917-927.

22. Sano T, Okuyama Y, Kobori O, Shimizu T, Morioka Y: Early gastric cancer. Endoscopic diagnosis of depth of invasion. Dig Dis Sci 1990, 35:1340-1344.

doi:10.1186/s13000-014-0206-8

Cite this article as: Yang et al:: Risk factors for depth of infiltration in the differentiated depressed early gastric carcinoma: a preliminary analysis. Diagnostic Pathology 2014 19:206.

\section{Submit your next manuscript to BioMed Central and take full advantage of:}

- Convenient online submission

- Thorough peer review

- No space constraints or color figure charges

- Immediate publication on acceptance

- Inclusion in PubMed, CAS, Scopus and Google Scholar

- Research which is freely available for redistribution

Submit your manuscript at www.biomedcentral.com/submit
( Biomed Central 